\title{
Assessing the ability of rural areas to fulfill multiple societal demands
}

\author{
Pinto-Correia T., Guiomar N., Guerra C. and Carvalho-Ribeiro S.
}

Abstract: Rural areas are changing through a process of multifunctional transition. New societal expectations, including countryside consumption and protection, increasingly determine the way rural space is used. There is a pressing need to grasp the new relative balance between these drivers of the rural space, in each particular area, in order to target public intervention. Tackling differentiation within rural space will definitely contribute to developing the potential and vocation of each area while supporting territorial cohesion. In this context, sound analytical knowledge that reveals and characterizes this differentiation is required and novel analytical approaches are needed for this knowledge to be obtained. Based on the conceptual framework proposed by Holmes (2006, 2012), this paper presents two methodological pathways for defining a typology of European regions that considers the multifunctionality of rural areas today and the relative weight of the dimensions of production, protection and consumption. The classification is produced at Nomenclature Territorial Unit NUTS 2 level, using information derived from European statistical datasets compiling different cartographic sources. One of the methods used to develop a typology was a clustering approach while the other method used was an expert-based analytical procedure. Even when the limitations stemming from the data available for the whole of Europe are considered, the results are encouraging. The results show two different regional distributions in Europe. These distributions, which have some similarities but also certain differences, both reveal the general characteristics of NUTS 2 regions and shed new light on the ways in which societal expectations for production, protection and consumption might be spatially reconciled. The expert-based approach seems to produce a more faithful classification. Both typologies result in most regions being classified as pluri-active, or complex or multifunctional, which may indicate that multiple modes of rural occupancy are widely found in each region and therefore that a more detailed scale of analysis would be more likely to enable evidence-based decisions to be made.

Keywords; Typology; rural areas; transition to multifunctionality; indicators

Doi: 10.1016/j.landusepol.2015.01.031

Citação: Pinto-Correia T., Guiomar N., Guerra C. and Carvalho-Ribeiro S., 2015. Assessing the ability of rural areas to fulfill multiple societal demands. Land Use PolicyDOI 10.1016/j.landusepol.2015.01.031 